\title{
A Consciência Étnica do Trabalho Docente Indígena (1988-2018)
}

\author{
Ethnic Awareness of Indigenous Teaching Work In Ceará (1988-2018)
}

\section{Conciencia Étnica del trabajo de Enseñanza Indígena em Ceará (1988-2018)}

\author{
Franco, Roberto Kennedy Gomes ${ }^{1}$ (Redenção,Ceará, Brasil) \\ ORCID ID: http://orcid.org/0000-0002-8133-1025
}

\begin{abstract}
Resumo
Analisamos a formação da consciência étnica do trabalho docente indígena no Estado do Ceará, no Nordeste brasileiro, entre os anos de 1998-2018. Optou-se como fonte privilegiada, metodologicamente, a história de vida profissional centrada nas vozes das professoras e professores, que, dentre outras coisas, conscientemente reivindicam ao direito ao trabalho docente indígena, ou seja, pela retomada do protagonismo de uma educação escolar com os povos indígenas e não para os povos indígenas. Para o movimento indígena, politicamente, a garantia de uma educação escolar específica, diferenciada e intercultural, passa necessariamente pelo cumprimento da Legislação Escolar Indígena, onde tem-se assegurado que o professor tem que ser indígena. Isso quer dizer que a reivindicação política pelo direito ao trabalho docente indígena, reafirma a compreensão de "que o próprio educador deve ser educado" (MARX, 2002) pelo mundo físico da natureza e social da cultura indígena. A esse respeito, em seu indianismo de inspiração marxista, (MARIÁTEGUI, 2007), ao analisar a questão da educação indígena na América Latina, ainda nas primeiras décadas do século $X X$, já argumentava contra a alienante educação imposta pelos colonizadores, reivindicando a necessidade de uma educação anticapitalista, contra-hegemônica, autônoma e horizontalmente "promovida pelos próprios índios", o que necessariamente se articularia com a crítica prática da propriedade privada da terra. Para MARIÁTEGUI (2007), "o problema do índio é o problema da terra", portanto, uma questão de "educação para além do capital" (MÉSZÁROS, 2008).
\end{abstract}

Palavras-chave: Consciência Étnica. Trabalho e Docência.

\begin{abstract}
We analyzed the formation of ethnic awareness of indigenous teaching work in the state of Ceará, in Brazilian Northeast, between the years of 1998 and 2018. We selected as the preferenced source of our study the stories of teachers' professional life, who, among other things, consciously claim the right to indigenous teaching practice, that is, the resumption of the leading role of indigenous peoples in their own education. Politically, for the indigenous movement, the guarantee of a specific, differentiated and intercultural education necessarily requires compliance with the Indigenous School Legislation, which ensures that the community school teacher has to be indigenous. Thus, this means that the political claim for the right to indigenous teaching practice reaffirms the understanding that "the educator himself must be educated" (MARX, 2002) by the physical and social realities of indigenous culture. In this regard, Mariátegui (2007) analyzes the issue of indigenous education in Latin America, still in the first decades of the XX century, in the perspective of Marxist-inspired Indianism. The author argued against the alienating education imposed by the colonizers, claiming the need for an anti-capitalist, antihegemonic, autonomous and horizontal education "promoted by the Indians themselves", which would necessarily articulate with the criticism of private land-ownership. For Mariátegui (2007) "the Indian problem is the land problem", therefore, a matter of "education beyond capital" (MÉSZÁROS, 2008).
\end{abstract}

Keywords: Ethnic Awareness. Work and Teaching.

\footnotetext{
1 Professor da UNILAB - Universidade da Integração Internacional da Lusofonia Afro-Brasileira. robertokennedy@unilab.edu.br
} 


\section{Resumen}

Analizamos la formación de la conciencia étnica del trabajo de enseñanza indígena en el estado de Ceará, en el noreste de Brasil, entre los años 1998-2018. Fue elegida como fuente privilegiada, metodológicamente, la historia de la vida profesional centrada en las voces de maestros y profesores, quienes, entre otras cosas, reclaman conscientemente el derecho al trabajo de enseñanza indígena, es decir, al retomar el protagonismo de una educación escolar con el pueblos indígenas y no para pueblos indígenas. Para el movimiento indígena, políticamente, la garantía de una educación escolar específica, diferenciada e intercultural, necesariamente implica el cumplimiento de la legislación escolar indígena, donde se ha asegurado que el maestro debe ser indígena. Esto significa que el reclamo político por el derecho al trabajo de enseñanza indígena reafirma el entendimiento de que "el educador mismo debe ser educado" (MARX, 2002) por el mundo físico de la naturaleza y lo social de la cultura indígena. En este sentido, en su indigenismo de inspiración marxista (MARIÁTEGUI, 2007), al analizar el tema de la educación indígena en América Latina, incluso en las primeras décadas del siglo XX, ya argumentó en contra de la educación alienante impuesta por los colonizadores, alegando la necesidad de una educación anticapitalista, contrahegemónica, autónoma y horizontal "promovida por los propios indios", que necesariamente se articularía con la crítica práctica de la propiedad privada de la tierra. Para MARIÁTEGUI (2007), "el problema de los indios es el problema de la tierra", por lo tanto, una cuestión de "educación más allá del capital" (MÉSZÁROS, 2008).

Palavras-Clave: Conciencia étnica. Trabajo y enseñanza.

\section{Palavras iniciais}

Nós vamos pensar no processo educativo diferente, de subverter ao olhar do próprio índio, e se é para se ter uma história contada pelo próprio índio, então o índio vai lá, pesquisa seu povo e conte a sua própria história, sobre

a sua própria versão.

(Suzenalson Kanindé, liderança e professor indígena)

$\mathrm{Na}$ realidade latino-americana, os povos indígenas se configuram como um dos segmentos mais excluídos do ponto de vista econômico, habitacional, educacional e dos indicadores de saúde, como evidenciam as investigações sobre a produção material da existência desses indivíduos.

Historicamente, esse lugar subalterno se articula com as violências de classe, raça e etnia praticadas em nome da fé e da ganância mercantilista colonial/capitalista, seja através de genocídio (morte física de um povo) e/ou etnocídio (descaracterização e absorção de uma determinada cultura em relação à outra na história).

Sobre esse processo, Eduardo Galeano (2012, p.05) ensina que:

É a América Latina, a região das veias abertas. Desde o descobrimento até nossos dias, tudo se transformou em capital europeu ou, mais tarde, norteamericano, e como tal tem-se acumulado e se acumula até hoje nos distantes centros de poder. Tudo: a terra, seus frutos e suas profundezas, ricas em minerais, os homens e sua capacidade de trabalho e de consumo, 
os recursos naturais e os recursos humanos. O modo de produção e a estrutura de classes de cada lugar têm sido sucessivamente determinados, de fora, por sua incorporação à engrenagem universal do capitalismo. [...] A história do subdesenvolvimento da América Latina integra, como já se disse, a história do desenvolvimento do capitalismo mundial.

No Nordeste brasileiro, esse processo esteve atrelado à cultura do boi e da cana-de-açúcar, que transformadas em mercadorias de exportação, possibilitaram uma "colonização" que, nas palavras de Galeano (2012, p. 29), deflagrou "uma guerra que derramou rios de sangue, em cujas veias corriam sangue indígena".

Esse processo de (des)ocupação tinha como intencionalidade "limpar" o território dos chamados "selvagens". Para tanto, os povos indígenas foram violentados por aldeamentos religiosos, escravização, assassinatos em massa, mediante guerras e/ou disseminação de doenças com uso de armas biológicas (gripe, sarampo, tuberculose, varíola, entre outros vírus e/ou bactérias).

Ao longo desse 519 anos, apesar dos ataques violentos às suas culturas, fruto da necessidade de lucro dos "colonizadores" ou do processo de "educação"/“cristianização"/“civilização”, por parte da Igreja e do Estado, entretanto, os povos indígenas não deixaram de resistir, seja de maneira explícita/violenta ou por meio de formas dissimuladas, como o sincretismo cultural com os colonizadores.

Emerge desse cenário, de acordo com os resultados do Censo Demográfico do IBGE de 2010, aproximadamente 90.000 mil pessoas se declarando indígenas, representando $0,4 \%$ da população total do Brasil, sendo oficialmente identificadas cerca de 305 etnias e 274 línguas indígenas.

No espaço geográfico do Estado do Ceará, esse mesmo levantamento do IBGE (2010) revelou que existem em torno de 20 mil índios, divididos em 14 etnias (Tapeba, Tremembé, Pitaguary, Jenipapo-Kanindé, Kanindé de Aratuba, Potiguara, Tabajara, Kalabaça, Kariri, Anacê, Gavião, Tubiba Tapuia, Tapuba Kariri).

No tocante à oferta de educação escolar indígena, há oficialmente, para os povos indígenas no Ceará, apenas 42 escolas indígenas diferenciadas, interculturais e bilíngues, com cerca de 350 professores e aproximadamente 7 mil 
alunos.

Frente a esse cenário, analisamos, inspirados pelo materialismo histórico- dialético, a formação da consciência étnica do trabalho docente indígena no Estado do Ceará, no Nordeste brasileiro, entre os anos de 1998-2018.

Particularmente, optou-se como fonte privilegiada, metodologicamente, a história de vida profissional centrada nas vozes das professoras e professores, que, dentre outras coisas, conscientemente reivindicam o direito ao trabalho docente indígena, ou seja, à retomada do protagonismo de uma educação escolar com os povos indígenas e não para os povos indígenas, de uma escola construída horizontalmente.

Para o movimento indígena, politicamente, a garantia de uma educação escolar específica, diferenciada e intercultural, passa necessariamente pelo cumprimento da Legislação Escolar Indígena, onde tem-se assegurado que o professor tem que ser indígena, inclusive daquela mesma etnia onde trabalha, sendo um sujeito educado por aquela cultura, pela cosmovisão de mundo de seu povo, que compartilhe das histórias, das lutas e das vivências.

A esse respeito, vejamos o comentário da professora Angélica Anacé (2017),

O meu objetivo na nossa escola indígena é retomar nossos jogos indígenas, né que é o arco e flecha, a lança, o carregar tora. Então assim, eu sou uma, das atletas indígenas, onde só participei de um jogo indígena pois não teve mais esse jogo, e assim, eu vi que nós temos essa necessidade de recuperar esses jogos indígenas. Meus próprios alunos dizem assim: professora a gente vai pra quadra hoje né, eles esperam que a gente só vai aplicar aquela modalidade de hoje que é futebol que é o que mais faz a cabeça. Eu pretendo aqui, a partir desse ano, onde já estou ocupando essa vaga trabalhar jogos modernos e resgatar os jogos tradicionais que são os jogos indígenas. Então assim, o meu objetivo da minha formação é trabalha justamente isso a recuperação de todos os fatores culturais, com relação a dança, a música, ao esporte, estamos tentando recuperar tudo isso, a parte do teatro. Então eu não sei se a outra professora trabalhava isso, mas eu aprendi por ela não ser índia, por ela não ter consciência do que é ser índio, essa vontade, esse orgulho, então, não é desmerecendo, mas eu acho que pra ensinar as culturas tradicionais indígenas é melhor um índio ensinar pra outro índio. Se é uma pessoa que nunca viveu muito tempo naquela aldeia, ela não vai saber o que é viver, o que é índio, o que é sentir-se índio. Então, um dos meus objetivos é esse abordar todos os fatores culturais da escola relacionados, dança, esporte e tudo mais em relação a isso. O que eu puder já em relação a isso é o meu objetivo. 
A fala da professora, dentre outras coisas, oportuniza nosso destaque para a reivindicação política pelo direito à docência indígena e de luta pela retomada do protagonismo de uma educação escolar com os povos indígenas e não para os povos indígenas, de uma escola construída de baixo para cima.

Na mesma direção, temos a fala da professora do Povo Kanindé, Ivoneice (2015), quando pondera que:

Quando eu comecei aqui na escola indígena que não era esse prédio, eu ensinava debaixo das arvores, nas casas dos vizinhos, a gente percebe a diferença de lá para agora, pois antes muitas crianças cresciam com o entendimento de que não eram índios e diziam que aqui no Fernandes não tinha índios, mais, no entanto temos famílias na comunidade que dizem que não são índios, mais todos somos de uma única família e viemos do mesmo lugar, essas crianças estavam crescendo desse jeito não se reconhecendo enquanto tal, com o trabalho cultural desenvolvido pela escola, hoje as crianças, jovens, velhos, ou seja, toda a comunidade dizem que são índios.

Fica perceptível na análise das falas que alguns projetos, aulas e atividades, desenvolvidos pelos professores indígenas nas escolas diferenciadas, permitem-nos compreender com mais profundidade o processo formativo de conscientização étnica pelo qual passam os alunos indígenas. Uma vez que a escola tem o importante papel de formar culturalmente seus estudantes, isso nos faz compreender até que ponto a instituição tem utilizado os espaços possíveis para a resistência e protagonismo na execução da proposta diferencida, visto que é nesse ponto que se encontra a diferença de seu currículo em relação a outras escolas tradicionais brasileiras.

A entrevista do professor e liderança indígena João Kennedy Tapeba, 2017, reafirma essa reivindicação, ao pontuar que,

Nós enquanto comunidade indígena, o que nós fazemos, sentamos com o gestor e colocamos, olha a gente quer professores indígenas, não vamos aceitar de jeito nenhum um professor não índio aqui dentro, se vier um professor que não seja índio a escola fecha, eu, por exemplo, como liderança, deixei isso bem claro na minha comunidade, olha se vier um professor que não seja índio a gente vai fechar a escola, a escola vai parar porque a gente não vai aceitar nenhum professor que não seja índio, deixei bem claro. Um dia antes a gente se reuniu, a gente viu lá quem tinha se inscrevido, a gente ficou com essa preocupação, aí deixamos isso bem claro, aí foi esclarecido tudo. 
Apreende-se com essa radicalidade crítica sobre o exercício da docência por não-indígenas, uma consciência étnica indígena engajada no combate à discriminação étnico-racial. Umas das contradições denunciadas é que, limitado em sua formação, a prática desse docente não-indígena na sociabilidade colonizadora do capital é resultado de um processo educativo permeado pela memória histórica, hegemônica e dominante. Fica contundente nas entrevistas que professores nãoindígenas têm pouco ou quase nenhum engajamento com a epistemologia da educação escolar indígena diferenciada, salvo raras exceções.

Assim, a reivindicação política pelo direito ao trabalho docente indígena, reafirma a compreensão de "que o próprio educador deve ser educado" (MARX, 2002) pelo mundo físico da natureza e social da cultura indígena.

Aesse respeito, em seu indianismo de inspiração marxista, MARIÁTEGUI, militante engajado na luta pelo lugar histórico dos povos indígenas na luta de classes e pela transformação social, afirma que "a solução do problema do índio deve ser uma solução social. Seus realizadores devem ser os próprios índios", e ainda que "a revolução social historicamente precisa da insurreição dos povos coloniais".

Mariátegui, ao analisar a questão da educação indígena na América Latina, ainda nas primeiras décadas do século XX, articula a união indissociável entre "Educação e Economia", afirmando que,

O problema da educação não pode ser bem compreendido se não for considerado como um problema econômico e social. O erro de muito reformadores residiu em seu método abstratamente idealista, em sua doutrina exclusivamente pedagógica. Seus projetos ignoram a íntima engrenagem que há entre economia e a educação e pretenderam modificar esta sem conhecer as leis daquela. Consequentemente, não conseguiram reformar nada senão na medida em que as leis econômicas e sociais permitiram (MARIÁTEGUI, 1994, p. 65).

Como se percebe, para Mariátegui, "os programas e os sistemas de educação pública dependeram dos interesses da economia burguesa." e argumentava contra a alienante a educação imposta pelos colonizadores capitalistas, reivindicando a necessidade de uma educação anticapitalista, 
anticolonial, contra-hegemônica, autônoma e horizontalmente "promovida pelos próprios índios", o que necessariamente se articularia com a crítica prática da propriedade privada da terra. Finalmente, para MARIÁTEGUI (2007), "o problema do índio é o problema da terra", portanto, uma questão de "educação para além do capital" (MÉSZÁROS, 2008).

Emerge, então, como resultado da investigação, o fato de que a formação da consciência étnica das trabalhadoras e trabalhadores docentes sobre as "peculiaridades" do "fazer-se" (THOMPSON, 2002; 1981) docente indígena, compreende não somente o âmbito da institucionalização do saber científico, no espaço-tempo da instituição escolar, mas transpõe-se para as experiências educativas das lutas sociais, históricas, econômicas, políticas, dentre outras.

Segundo Aires, (2009, p. 18), ao analisar "à emergência do professor indígena como figura-chave nas mobilizações étnicas", no Estado do Ceará, Nordeste do Brasil,

É possível perceber uma mudança sensível dos discursos e ampliação dos elementos táticos usados pelo movimento indígena com a entrada em cena dos professores, como, por exemplo, o emprego de um vocabulário específico em sintonia com a linguagem utilizada nos documentos oficiais e a produção de um calendário de atividades relacionadas com as escolas indígenas, tais como festas, feiras, celebrações e inúmeros outros eventos. (AIRES, p. 35, 36).

Tendo como ponto de partida o florescimento desse cenário históricoeducativo, as narrativas de consciência e luta desses docentes indígenas são possíveis "outras histórias" (HOBSBAWM, 1998) e memórias do movimento da educação escolar indígena diferenciada, e, além disso, evidencia-se também como experiência de luta por terra, trabalho, saúde, educação, dentre outros meios mínimos necessários à produção da vida para além do capital.

Segundo Carneiro da Cunha (2009, p. 125)

A história dos povos indígenas no Brasil está mudando de figura. Até os anos 1970, os índios, supunha-se, não tinham nem futuro, nem passado. Vaticinava-se o fim dos últimos grupos indígenas, deplorava- se sua assimilação irreversível e a sua extinção tida por inelutável diante do capital que se expandia nas fronteiras do país. 
Assim, ao analisarmos a experiência da docência indígena entre os povos indígenas, o observado é que, em suas relações sociais com o meio ambiente, esses são simultaneamente educandos e educadores dos locais onde vivem e aos quais se adaptam ao longo de suas trajetórias, aliando as características específicas de cada eco-sistema aos seus corpos e, assim, aprendendo a prover suas existências bioculturais.

Aqui, cabe ainda, destacarmos a indispensável contribuição de E. P. Thompson, para a investigação em história social da educação escolar indígena, quando faz a análise comparativa entre Educação e Experiência, ao afirmar que,

A experiência modifica, às vezes de maneira sutil e às vezes radicalmente, todo o processo educacional; influencia os métodos de ensino, a seleção e o aperfeiçoamento dos mestres e o currículo, podendo até mesmo revelar pontos fracos ou omissões nas disciplinas acadêmicas tradicionais e levar à elaboração de novas áreas de estudo." (THOMPSON, 2002, p. 13)

Tal premissa vincula os trabalhadores docente indígenas a um processo de adaptação social ao meio em que vivem, trazendo a necessidade de se refletir os professores e professoras indígenas na qualidade de agentes históricos, impregnados de uma existência concreta, e que, partindo da produção material da existência, o percebamos como seres sociais que, pela sua "experiência" (THOMPSON, 1981), têm contato, dialogam, determinam e são determinados pela realidade social em que estão inseridos.

Tais reflexões, metodologicamente, conduzem-nos para o trabalho com as histórias da vida profissional de professores e professoras indígenas, das experiências dos que vivenciam o cenário histórico-educativo em questão. Isso, na prática, significa desenvolver procedimentos interpretativos que assumem a função social de "escovar a história a contrapelo" (BENJAMIN, 1994) sobre as "experiências transmissíveis de boca em boca" (BENJAMIN, 1994, p. 115), pelos docentes indígenas no estado do Ceará, Nordeste do Brasil.

Para Benjamin (1994, p.198), 


\begin{abstract}
A experiência que passa de pessoa a pessoa é a fonte a que recorrem todos os narradores. $E$, entre as narrativas escritas, as melhores são aquelas que menos se distinguem das histórias orais contadas pelos inúmeros narradores anônimos.
\end{abstract}

A gestação desse sentido para a história da educação é de fundamental importância, pois assim nos permite entender que o contexto histórico-educativo dos povos indígenas cearenses possui uma espacialidade e uma temporalidade que não se desenvolvem nem se desenrolam além da vida cotidiana como em uma realidade virtual ou meramente discursiva. Pelo contrário, possuem uma materialidade inscrita no desenrolar do processo histórico mais amplo da história social humana.

Complementarmente, Magalhães (1999, p. 8-9), afirma que,

Os professores na história é uma forma particular de dizer que a docência, a mestria e os professores tiveram e têm um papel central como construtores do humano, nos planos material, civilizacional e antropológico. E essa dimensão afigura-se tão estimulante como ignorada pelo conhecimento historiográfico.

Posto isso, interpretamos a história da educação escolar indígena como um processo relacional diluído no fazer cotidiano, possuindo uma temporalidade e uma espacialidade específica e singular, inscrita tanto na objetividade, quanto na subjetividade humana.

Isso porque, historicamente, tornamo-nos "nós" pelo trabalho educativo, somos nossas necessidades efetivas. Diluídos no meio físico da natureza e social da cultura, vamos, coletivamente, determinando e sendo determinados enquanto seres humanos. É pelo intercâmbio material da vida em sociedade que se educa a relação corporal de cada indivíduo com o meio ambiente. Todos ao mesmo tempo são trabalhadores e trabalhados pelo meio no qual vivem e ao qual se adaptam ao longo da evolução como espécie biológica. O ser humano, portanto, vai gradativamente aprendendo a aliar suas necessidades às características específicas de cada ecossistema e, assim, consegue prover pelo trabalho educativo sua subsistência.

Na prática de nossa investigação, isso significa, mediante o materialismo histórico-dialético, desenvolver procedimentos analíticos onde "pesquisar em história da educação é investigar o objeto educação sobre a perspectiva histórica." (SAVIANI; 
LOMBARDI; SANFELICE, 1998, p.11, 12). Pelo menos, assim tem sido o fio-condutor constitutivo de nossa escrita da História da Educação Escola Indígena Diferenciada.

Os caminhos percorridos pela pesquisa expressam, portanto, a dialeticidade das narrativas dos professores indígenas que, no jogo contraditório entre lembranças/esquecimentos, possibilitam estudar os modos pelos quais os povos indígenas historicamente situados, materialmente, constituem seus modos de viver.

\section{Docência Indígena e Consciência étnica}

A consciência humana se modifica com toda mudança sobrevinda em suas condições de vida, em suas relações sociais, em sua existência social.

(Karl Marx)

Em nossa interpretação, esse processo de formação da consciência étnica do trabalho docente indígena é fruto do metabolismo psíquico vivenciado pela experiência do movimento indígena no contexto de redemocratização pós-ditadura civil- empresarial-militar, ou seja, da formação de uma consciência política na qual o engajamento dos povos indígenas busca fortalecer a luta por melhores condições de vida.

Estrategicamente, essa consciência étnica dos povos indígenas no contexto da América Latina, com foco no Nordeste do Brasil, faz-se na luta pela retomada da terra expropriada em nome da fé e da ganância mercantilista colonial/racista/capitalista, pela retomada étnica da identidade silenciada/negada por violentos genocídios e etnocídios. Além disso, esse fazer-se, dialeticamente, evidencia-se também como território anticolonial da educação escolar indígena, estabelecida por ampla legislação educacional pós-1988, com a nova Constituição.

A esse respeito, Streck, Adams e Moretti (2010, p. 24, 25), comentam que

A América Latina é fruto das heranças coloniais, mas ao mesmo tempo das resistências [...] Para "escravar uma pedagogia emancipadora com as características de nossos povos, é necessário partir do encontro contraditório, mas indissociável, entre a cultura europeia, a indígena e a africana. A primeira identificada com o projeto da modernidade e as duas outras, as dominadas, 
que carregam até hoje as consequências em termos de subalternidade e resistência: a colonialidade. Como aparecem historicamente os projetos pedagógicos nesse contexto? Contribuíram para superar as inferioridades e dependências ou para legitimar a crença epistêmica de que não somo capazes e por isso temos que ter o aval do norte para validar nossos caminhos de emancipação humana e social? Acreditamos que a atitude adequada não seja negar o legado da modernidade, mas reconhecê-lo e contextualiza-lo histórica e epistemologicamente questionando, contudo, a lógica da monocultura eurocêntrica e abrir caminhos para outros paradigmas. Superar a colonialidade significa deixar de ser apêndice das transformações e assumir igualmente o protagonismo da construção de sociedades que valorizem as características da diversidade dos nossos povos.

De forma complementar, Oliveira (2016, p. 13) afirma ainda que

As vozes indígenas contra a colonização só se fizeram conhecer recentemente, nas últimas décadas, quando as lutas por demarcação de seus territórios, ampliadas e repercutidas por um arco de alianças (igrejas, universidades, grupos de direitos humanos), começaram a chegar até a opinião pública, em aberta contradição com as imagens idealizadas sobre a construção do país e com a postura tutelar do indigenismo. Foi este, no final da década de 1970, o momento em que, creio, iniciou-se tal ruptura.

As explicações de Alexis Leontiev no livro O Desenvolvimento do Psiquismo, em nosso entender, possuem relação direta com esse processo de metabolismo psíquico vivenciado pela experiência dos indígenas. Ao analisar o aparecimento e o desenvolvimento histórico da consciência, Leontiev (1978, p. 83, 88, 89) diz:

A consciência humana não é uma coisa imutável. Alguns dos seus traços característicos são, em dadas condições históricas concretas, progressivos, com perspectivas de desenvolvimento, outros são sobrevivências condenadas a desaparecer. Portanto, devemos considerar a consciência (o psiquismo) no seu devir e no seu desenvolvimento, na sua dependência essencial do modo de vida, que é determinado pelas relações sociais existentes e pelo lugar que o indivíduo considerado ocupa nestas relações. Assim é um objecto social, o produto de uma prática social, de uma experiência social de trabalho. Por fim, a consciência individual do homem só pode existir nas condições em que existe a consciência social. A consciência é o reflexo da realidade, refractada através do prisma das significações e dos conceitos linguísticos, elaborados socialmente. A consciência do homem é a forma histórica concreta do seu psiquismo.

Dessa forma, a produção histórico-social de uma consciência étnica, engajada na luta contra o preconceito étnico-racial imposto pelo colonialismo/capitalismo, tem relação com a necessidade cotidiana de uma educação política entre os povos indígenas. 


\title{
Em busca dessa educação política, o professor e liderança indígena João
}

Kennedy Tapeba, 2017, argumenta sobre a luta pela Terra que:

\begin{abstract}
A retomada de nossa Terra é um processo de formação política e cultural do nosso povo, de nossa juventude, de nossos alunos que tão crescendo. Hoje nós temos professores que cresceram dentro dessa luta de retomada de nossa terra, temos jovens que militam na AJIT (Articulação de Jovens Indígenas Tapebas), por exemplo, que hoje são professores por conta de que cresceram nessa luta, entendendo que sem a terra não vai ter um posto de saúde, sem a terra não vai ter uma escola, sem a terra não vai gerar o emprego, muitas vezes que muitos professores hoje tem, devido a educação, ou a escola, ou a saúde, não vai ter por que? Porque não tem terra, porque não vai ter terra?, por que os nossos troncos velhos, os nossos anciões, tão morrendo, aos poucos tão morrendo, quem é que vai dar continuidade a essa luta, se o meu aluno que é da minha escola, da minha sala, não tem essa formação política e cultural de luta, porque eu aprendi o que? Que eu preciso lutar por um direito meu que foi tirado, se eu não lutar ninguém vai lutar. Então eu cresci aprendendo isso, eu preciso valorizar o meu povo, valorizar a minha cultura, valorizar o que eu sou, a minha identidade que eu tenho, mas muitos tão crescendo sem valorizar isso por que não lutam, não ficam a frente de uma retomada, não passam um dia dentro de uma retomada correndo perigo mas que é bom, que a gente acha, eu pelo menos gosto quando tem uma retomada, por que ta todo mundo reunido, todo mundo trocando ideias, todo mundo ta la ansioso pronto pra lutar, se chegar um posseiro com o carro do batalhão de choque vamos todo mundo pro enfrentamento e ninguém recua, por conta de que? Por conta de que a formação política e cultural que vai desenvolver a identidade indígena daquele jovem."
\end{abstract}

Tem-se a apresentação da necessidade imediata que desencadeia esse processo de conscientização étnica. É no fazer-se sujeito político, que reivindica melhores condições de existência para si e para os outros, que o professor indígena João Kennedy Tapeba experiencia a formação de uma postura ativa e engajada. De forma complementar, segundo Antunes (1997, p. 117)

Decisivo aqui é referir que a consciência é originada no interior da vida cotidiana. É na cotidianidade que as questões são suscitadas e as respostas dos indivíduos e das classes são uma constante busca de indagações que se originam na vida cotidiana, onde as questões lhes são afloradas. As respostas às questões mais complexas são, entretanto, mediatizadas.

Contra os antagonismos decorrentes da sociabilidade colonizadora do capital, contundentemente é sentida, nas falas, a emergência histórica de um engajamento político pelo direito ao trabalho docente indígena.

Esse fato pode ser interpretado como de transição da consciência em si até a consciência para si, conceitos trabalhados tanto na obra a Miséria da Filosofia 
quanto na Ideologia Alemã, por Marx e Engels, ao analisarem especificamente o ato de produção da consciência nos seres humanos.

Epistemologicamente, a consciência em si é apresentada como uma práxis individual, que tem a existência engajada apenas para 0 ato acrítico/estranhado da produção dos meios necessários ao viver, sem consideração pelos aspectos políticos ou críticos em relação ao contexto social/coletivo em que se vive. A consciência para si trata-se do inverso, ou seja, de uma práxis coletiva de associação entre pessoas que se engajam conscientemente pela transformação histórico-social da realidade.

Na visão de Lukács sobre o movimento de formação da consciência (2001, p. 118), os indivíduos

elevam-se até o ponto de adquirirem uma voz cada vez mais articulada, até alcançarem a síntese ontológico-social de sua singularidade, convertida em individualidade, como gênero humano, convertido neles, por sua vez, em algo consciente de si.

Com suporte em tal plataforma conceitual, o presente texto, ao analisar a consciência étnica compartilhada pelos professores indígenas engajados politicamente na luta pelo direito ao trabalho docente, objetiva dialeticamente compreender também as peculiaridades do trabalho docente indígena no Estado do Ceará, no Nordeste brasileiro, entre os anos de 1988-2018.

É possível observar esse processo de tomada de consciência, por exemplo, na seguinte fala de Weibe Tapeba, liderança indígena do povo Tapeba:

\begin{abstract}
Então a escola indígena, escola diferenciada, escola específica, a escola intercultural, a escola bilíngue e multilíngue, ela deve estar voltada para o fortalecimento das identidades indígenas, para a valorização do patrimônio cultural, sobretudo para o fortalecimento do projeto societário dos povos indígenas, não é apenas letramento, não é apenas leitura, não apenas matemática, não apenas geografia, também formação de quadros de lideranças indígenas, também é proposição de política, de etnodesenvolvimento, de gestão de território e de luta pela demarcação de territórios indígenas que serão demarcados, a escola também está voltada também para o modelo de gestão territorial.
\end{abstract}

Emerge da análise da fala de Weibe Tapeba, a percepção de que os professores indígenas, de forma consciente, lutam politicamente pelo movimento da 
educação escolar indígena diferenciada, como instrumento de combate à discriminação étnico- racial.

De forma complementar, a fala de João Kennedy Tapeba (2017), liderança e professor indígena, coloca que

\begin{abstract}
A escola indígena diferenciada tem uma função social, que é mais do que transmitir conteúdos, é para ser lugar de resistência, de luta pela terra, pois ela tem um papel muito maior do que aquele papel burocrático de transmissão da norma culta da língua, da matemática, do português, da história e geografia tradicional, que é o currículo das disciplinas, imposto por esse processo colonizador de 500 anos.
\end{abstract}

Aprendemos com a fala de João Kennedy Tapeba que a educação escolar indígena diferenciada tem uma função social de disputa contra a exclusão colonial/capitalista, ao tempo em que reivindica o direito à terra, mediante o exercício de práticas culturais plurais que evocam uma ancestralidade de raízes históricas profundas, suprimidas pela escrita hegemônica da História.

O lugar social da cultura ancestral indígena na construção da história do Brasil também é percebido na falas do povo Anacé, quando evidenciam a luta com a Secretaria Estadual de Educação para a criação, dentro do currículo das escolas indígenas, de disciplinas diferenciadas e específicas sobre a história e a memória do povo anacé, como, por exemplo, as disciplinas de arte, espiritualidade indígena e expressão corporal. Segundo os relatos de Júnior Anacé (2017), a expressão corporal "trabalha o corpo em si né, é tipo como que fosse uma educação física mas voltado pra história indígena". Em nossa visita a campo, tivemos acesso a informações sobre o trabalho com projetos.

Sobre isso, em resumo, temos a seguinte fala da docente Angélica Anacé (2017):

A gente trabalha uma semana de um projeto chamado jogos indígenas. Então, no nosso calendário já tem os jogos indígenas. Porque quem faz o calendário das coisas indígenas hoje é a SEDUC, mas a escola indígena, quando ela tem autonomia de criar o seu próprio calendário e colocar as festas, as danças, pois é com a diversidade que a gente trabalha dentro das escolas. Tipo, a gente vai trabalhar num projeto dos jogos indígenas, aí na semana indígena, que é a semana do índio que chama, a gente trabalha de segunda a sexta, e no sábado tem as culminâncias que a gente trabalha voltada pra arte, cultura indígena, por que a gente passa a semana todinha 


\begin{abstract}
trabalhando com o infantil até o nono ano, e o EJA médio que é exatamente pra trabalhar essa diversidade intercultural. Por que a gente pegou alguns alunos do sexto ao nono ano e até pra trabalhar a história do nosso próprio povo, dos parentes e assim a gente ia trabalhando. Esse ano quem ganhou, por que tem que ter a campeã né, de tudo isso, a campeã foi a sala de terceiro ano com a história do nosso povo, onde foi mostrada aqui como é que é assar o peixe na brasa, levar os alunos pra mata, mostrar como é que sobe, bota os alunos pra subir nas arvores. Então, a gente procura sempre trabalhar essa diferença com os alunos pra poder eles compreender e entender, por que uma coisa é a história que nem algum de vocês falaram hoje, e outra história é vivenciar é pôr em pratica. $\mathrm{E}$ a gente pra não deixar essa nossa cultura morrer, acabar com tudo, a gente tem que repassar, por que eu já vivi isso, o Júnior viveu, esse jovem já não vive mais o que é essa cultura, então ele tem que estudar agora pra aprender de novo, é resgatar, como diz a história. Resgatar a história e não por só no papel é preciso pôr em pratica. $\mathrm{E}$ é isso que a gente procura fazer dentro das escolas indígenas hoje.
\end{abstract}

Nesse mesmo sentido, temos a fala da docente Kanindé, Ivoneice (2015), quando pondera que:

Sim, já vejo mudanças porque logo no início quando eu comecei aqui na escola indígena que não era esse prédio, eu ensinava debaixo das arvores, nas casas dos vizinhos, a gente percebe a diferença de lá para agora, pois antes muitas crianças cresciam com o entendimento de que não eram índios e diziam que aqui no Fernandes não tinha índios, mais, no entanto temos famílias na comunidade que dizem que não são índios, mais todos somos de uma única família e viemos do mesmo lugar, essas crianças estavam crescendo desse jeito não se reconhecendo enquanto tal, com o trabalho cultural desenvolvido pela escola, hoje as crianças, jovens, velhos , ou seja, toda a comunidade dizem que são índios.

Fica perceptível na análise das falas que alguns projetos, aulas e atividades, desenvolvidos pelos professores indígenas nas escolas diferenciadas, permitem-nos compreender com mais profundidade o processo formativo pelo qual passam os alunos indígenas. Uma vez que a escola tem o importante papel de formar culturalmente seus estudantes, isso nos faz compreender até que ponto a instituição tem utilizado os espaços possíveis para a resistência e protagonismo na execução da proposta diferencida, visto que é nesse ponto que se encontra a diferença de seu currículo em relação a outras escolas tradicionais brasileira.

Sobre o lugar social da cultura ancestral indígena na construção da história do Brasil, Suzenalson Kanindé, liderança e professor indígena, aponta que,

Entre os professores é uma tática descolonizar o processo de educação do europeu, subverter essa história através de um olhar do próprio índio, 


\begin{abstract}
simplesmente entender o que é que o próprio índio quer. Nessa linha de descolonização do processo da educação, nós encontramos uma coisa interessante, não só de se contar história, mas de se produzir também uma história que era subvertida antigamente pelo olhar do colonizador, que é esse negócio que o cara vai lá ver a história do povo e conta, nós não, nós vamos pensar no processo educativo diferente, de subverter ao olhar do próprio índio, e se é para se ter uma história contada pelo próprio índio, então o índio vai lá, pesquisa seu povo e conte a sua própria história, sobre a sua própria versão.
\end{abstract}

Aprendemos com a fala de Suzenalson Kanindé que a educação escolar indígena diferenciada passa a ser também espaço da disputa política "para se ter uma história contada pelo próprio índio", ao tempo em que os índios reivindicam o direito a existir, mediante o exercício de práticas culturais plurais que evocam uma ancestralidade de raízes históricas profundas, suprimidas pela historiografia tradicional.

A esse respeito, Oliveira (2016, p. 29), afirma que isso ocorre porque, "a memória que os movimentos e organizações indígenas tentam construir na contemporaneidade é muito diferente das representações do romantismo."

Dessa forma, interpretamos a docência indígena como experiência social na medida em que, dialeticamente, sujeitos históricos vivenciam as tramas da vida cotidiana, organizam sua vida em um conjunto de práticas, como pensamentos, ideias e sentimentos, em relações de reciprocidade e de interesses, organizações familiares e de parentesco, nas relações de trabalho, nas formas de exercícios e (des)estruturação de poderes, nas relações de dominação e de resistência; enfim, nas distintas maneiras de sociabilidade engendradas historicamente como necessidades e valores, para a história da educação.

Em nossas hipóteses, em função de uma causa coletiva que se remete também a necessidades individuais, em prol da luta por terra, trabalho, educação, saúde, dentre outros meios mínimos necessários à produção da vida para além do capital, os docentes indígenas passam historicamente a assumir uma posição de sujeito político ultrapassando a si próprios, ou seja, indo além da mera individualidade indígena.

Em Gramsci (2004, p. 43), isso decorre do fato de que 


\begin{abstract}
O homem, que em certo momento se sente forte, com a consciência da própria responsabilidade e do próprio valor, não quer que nenhum outro lhe imponha sua vontade e pretenda controlar suas ações e seu pensamento. Porque parece um cruel destino aos humanos serem dominados por este instinto, o de quererem devorar-se uns as outros, em vez de fazerem convergir as forças unidas para a luta.
\end{abstract}

Em nossa interpretação, deflagrado pelo movimento indígena, o trabalho docente indígena diz respeito a esse processo histórico de tomada de consciência política e de mobilização social por direito à cultura para vidas em experiências corporais indígenas, pois evidencia a compreensão do momento em que grupos sociais oprimidos, ao assumirem uma posição além de si, em função de uma causa coletiva, passam a associar-se. A ação coletiva dos docentes indígenas, ao abandonar a fatídica posição individual de estar meramente em si, enseja a análise da pedagogia política dos movimentos sociais de contestação que resistem ao tempo e permanecem presentes até nossos dias.

\title{
Palavras derradeiras
}

"A esperança indígena é absolutamente revolucionária"

(Mariátegui)

O modo de produção capitalista vivencia um momento de profunda crise de restruturação no modo de regulação produtiva, econômica, política e social, refletindo, entre outros aspectos, no aumento assustador, como no caso do Brasil, da vulnerabilidade social.

No campo dos direitos indígenas, a situação não é diferente: é notório o aumento da violência contra os povos indígenas, que, na alvorada de 2019, é marcada pelo modo de produção mercantilista/colonial/capitalista/racista. Vivemos uma conjuntura na qual cotidianamente os noticiários anunciam o assassinato ao direito a existir de uma diversidade étnica que resiste ao longo da história desses 519 anos.

Constata-se, portanto, que o movimento indígena busca sobreviver diante do constante ataque da lógica do capital, valendo ressaltar que, histórica e gradativamente, a classe dominante se organiza para conter toda e qualquer forma de movimento social que incida em conquistas para os setores menos favorecidos da 
população, reprimindo- os pela força das ameaças, violência e/ou cooptando-os, pelo menos assim é possível observar nas entrevistas dos ativistas.

Indiscutivelmente, como se pode ver pelos relatos do docentes indígenas, a organização consciente de grupos não-hegemônicos, como o das trabalhadoras e trabalhadores da educação escolar indígena, não é um evento que favoreça o grupo hegemonicamente dominante, mas, pelo contrário, quanto mais desarticulada e fragmentada se apresenta aos grupos subalternos, mais frágil e estranhada se torna diante da implacável desregulamentação que lhe é imposta.

Essa contradição se dá porque a exaltada sociedade urbano-industrial, que estabeleceu a alfabetização em massa pela primeira vez no Ocidente, não eliminou com isso os antagonismos de classe, raça e etnia. Infelizmente, a "eficácia" não só da escola, como de todas as relações entre os seres humanos, parece ser direcionada pela lógica produtora do lucro, o que, consequentemente, traz em si a exclusão não só dos povos indígenas, como de toda e qualquer atividade que se diferencie da dinâmica desigual e combinada de produção, circulação e consumo das mercadorias geradoras de lucros que tem, na cidade, sua forma mais elaborada e, portanto, "determinante" das demais espacialidades.

Por fim, a formação da consciência étnica das trabalhadoras e trabalhadores docentes indígenas, faz-se pela retomada da terra expropriada, pelo reconhecimento da identidade violentada por genocídios e etnocídios, e ainda, como território anticapitalista da educação escolar indígena na luta por terra, trabalho, educação, saúde, dentre outros meios mínimos necessários à produção da vida para além do capital.

\section{Referências Bibliográficas}

AIRES, Max Maranhão Piorsky. De aculturados a índios com cultura: estratégias de representação do movimento de professores tapebas em zonas de contato. In: Max Maranhão P. AIRES. (Org.). Políticas interculturais e escolas indígenas no Nordeste brasileiro. Fortaleza: EDUECE, 2009.

ANACÉ, Angélica. Entrevista concedida a Roberto Kennedy Gomes Franco, 2017. ANACÉ, Júnior. Entrevista concedida a Roberto Kennedy Gomes Franco, 2017. 
BENJAMIM, Walter. Magia e técnica, arte e política: ensaios sobre literatura e história da cultura. Tradução Sérgio Paulo Rouanet. - 7. ed. - São Paulo, 1994.

CUNHA, Manuela Carneiro da. Por uma história indígena e do indigenismo. In: Cultura com aspas e outros ensaios. São Paulo: Cosac Naify, 2009.

GALEANO, Eduardo. As veias abertas da América Latina. Porto Alegre: L\&PM, 2012.

GRAMSCI, Antônio. Os Intelectuais e a Organização da Cultura. Tradução de Carlos Nelson Coutinho. $7^{\text {a }}$ Edição. Editora Civilização brasileira.1989.

HOBSBAWM, Eric. A outra história: algumas reflexões. In: KRANTZ, Frederick (org.). A outra história: ideologia e protesto popular nos séculos XVII a XIX. Tradução: Ruy Jungmany. Rio de Janeiro: Jorge Zahar Editor, 1998.

IBGE - Instituto Brasileiro de Geografia e Estatística. Características gerais dos indígenas no Censo Demográfico 2010 - resultados do Universo. Rio de Janeiro: IBGE, 2012.

KANINDÉ, Ivoneice. Entrevista concedida a Francisco Wallison Batista De Lima, 2015.

KANINDÉ, Suzenalson. Mesa-redonda. Universidade da Integração Internacional da Lusofonia Afro-Brasileira, 2017.

LEONTIEV, A.N. (1972) O desenvolvimento do psiquismo. Trad. Manuel D. Duarte.

Lisboa: LUKÁCS, György. Ontologia do Ser Social. A Falsa e a Verdadeira Ontologia de Hegel. Tradução de Carlos Nelson Coutinho. São Paulo: Ciências Humanas, $1979 \mathrm{~b}$.

LUKÁCS, György. Ontologia do Ser Social. Os Princípios Ontológicos Fundamentais de Marx. Tradução de Carlos Nelson Coutinho. São Paulo: Ciências Humanas, 1979a.

MAGALHÃES, Justino; ESCOLANO, Agustín. Os Professores na História. Porto: Sociedade Portuguesa de Ciências da Educação/ Sociedad Española de Historia de la Educación, 1999.

MARIÁTEGUI, José Carlos. Mariátegui sobre educação. São Paulo: Xamã, 2007.

MARIÁTEGUI, José Carlos. Sete ensaios de interpretação da realidade peruana. São Paulo: Expressão Popular, 2010. 
MARX, Karl. Miséria de la Filosofia. Buenos Aires: Ed. Actualidade, 1927.

MARX, Karl. Manuscritos Econômico-filosóficos. Tradução de Jesus Ranieri, São Paulo: Boitempo: 2004.

MARX, Karl e ENGELS, Friedrich. Sobre o Sindicalismo. Seleção de Textos de C. Bastien; Tradução do Francês de João Manuel. Pontos de Vista, São Paulo, 1968.

MARX, Karl. A Ideologia Alemã. Karl Marx e Friedrich Engels; [introdução de Jacob Gorender]; tradução Luis Claudio de Castro e Costa. - São Paulo: Martins Fontes, 1998. (Clássicos).

MARX, Karl. Crítica ao programa de Gotha. In: MARX, Karl. ENGELS, Friedrich. Obras escolhidas. São Paulo: Alfa-ômega, 1980.

MARX, Karl. 018 de Brumário e Cartas a Kugelmann. Rio de Janeiro: Paz e Terra, 1997.

MARX, Karl. O Capital - Crítica da Economia Política. Livro Primeiro - O Processo de Produção do Capital - Volume I. Tradução de Reginaldo Sant'Anna. $4^{a}$ edição, 1980, Rio de Janeiro: Editora Civilização Brasileira S.A.

MARX, Karl. O Capital: crítica da economia política. Vol. I, Livro I - O processo de produção do Capital. 13 ed. Rio de Janeiro: Bertraud do Brasil, 1989.

MARX, Karl. Teses sobre Feuerbach. São Paulo: Martins Fontes, 2002.

MARX, Karl; ENGELS, Friedrich. A Ideologia Alemã. 3.ed. São Paulo: Livraria Editora Ciências Sociais, 1982.

MARX, Karl; ENGELS, Friedrich. Manifesto comunista. São Paulo, SP: Boitempo Editorial, 2007.

MÉSZÁROS, István, A educação para além do capital. São Paulo: Boitempo, 2008.

MÉSZÁROS, István. Para além do capital: rumo a uma teoria da transição / István Mészarós; tradução Paulo Cezar Castanheira, Sérgio Lessa. 1.ed. revista. São Paulo: Boitempo, 2011.

MUNDURUKU, Daniel. O Caráter Educativo do Movimento Indígena Brasileiro (1970- 1990), São Paulo: Paulinas, 2012.

OLIVEIRA, João Pacheco de. O Nascimento do Brasil e outros ensaios: "pacificação", regime tutelar e formação de alteridades. Rio de Janeiro: Contra Capa, 2016. 
PORTELLI, Alessandro. Forma e significado na história oral. A pesquisa como experimento em igualdade. Projeto História, 14, revista do Programa de Estudos Pós-Graduados em História e do Departamento de História da PUC-SP, 1997.

POTIGUARA, Rita Elizangela Pereira da Silva. Entrevista concedida a Roberto Kennedy Gomes Franco, 2017.

SAVIANI, Dermeval. O debate teórico e metodológico no campo da História e sua importância para a pesquisa educacional. IN: SAVIANI, Dermeval; LOMBARDI, José Claudinei; SANFELICE, José Luís (orgs). História e História da Educação: o debate teórico- metodológico atual. Campinas: Autores Associados/HISTEDBR, 1998. pp.715.

SAVIANI, Dermeval. O debate teórico e metodológico no campo da história e sua importância para a pesquisa educacional. IN: SAVIANI, Dermeval; LOMBARDI, José Claudinei; SANFELICE, José Luís (orgs). História e história da educação: o debate teórico- metodológico atual. Campinas: Autores Associados/HISTEDBR, 1998.

SOUZA, Maria Cecília Cortez Christiano de. A Escola e a memória. Bragança Paulista: IFAN- CDAPH. Editora da Universidade São Francisco/EDUSF, 2000.

STRECK, D; ADAMS, T; MORETTI, C. Pensamento pedagógico em nossa América: uma introdução. In: STRECK, D. (Org.). Fontes da Pedagogia latino-americana: uma antologia. Belo Horizonte: Autêntica, 2010. pp. 19-35.

TAPEBA, João Kennedy. Entrevista concedida a Roberto Kennedy Gomes Franco, 2017.

TAPEBA, Weibe. II Conferência Nacional de Educação Escolar Indígena, 2017.

THOMPSON, E. P. Prefácio. In: THOMPSON, E. P. A Formação da Classe Operária Inglesa. Tradução Denise Bottman. Ed. Rio de Janeiro: Paz e Terra, 2002.

THOMPSON, E.P. A miséria da teoria, ou um planetário de erros. Rio de Janeiro: Zahar, 1981.

THOMPSON, E.P. As peculiaridades dos ingleses e outros artigos. Campinas: Editora da Unicamp, 2001.

THOMPSON, Edward. Os românticos: a Inglaterra na era revolucionária. Rio de Janeiro: Paz e Terra, 2002. 


\section{Revista Labor}

Programa de Pós-graduação em Educação, Universidade Federal do Ceará

Fortaleza-CE-Brasil

\section{Roberto Kennedy Gomes Franco}

Redenção, CE, Brasil

Pós-doutor em História da Educação pela Universidade de Lisboa/Portugal. Doutor em Educação Brasileira (UFC). Mestre em Ciências da Educação (UFPI). Graduado em História (UFC). Professor da Universidade Federal da Integração Internacional da Lusofonia Afro-Brasileira UNILAB, atuando no Mestrado Interdisciplinar em Humanidades - MIH, Coordenador do Grupo Interdisciplinar MarxistaGIM/UNILAB; Membro do GEPI (Grupo de Estudos com os Povos Indígenas). Coordenador de Área do Programa Institucional de Bolsas de Iniciação à Docência - Pibid, no subprojeto Interdisciplinar de História/Sociologia/Unilab/Ceará.

Email: robertokennedy@unilab.edu.br

Link do Lattes: http://lattes.cnpq.br/9731559583032992

Recebimento: $11 / 06 / 2020$

Aprovação: $15 / 06 / 2020$

\section{Q.Code}

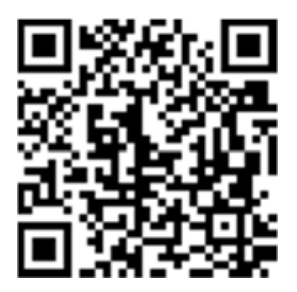

\section{Editores-Responsáveis}

Dr. Enéas de Araújo Arrais Neto, Universidade Federal do Ceará, UFC, Ceará, Brasil

Dr. Sebastien Pesce, Universidade de Orléans, França 